INRA Prod. Anim.,

2013, 26 (2), $117-128$

\title{
La fonction de lactation : régulation de la biosynthèse des constituants du lait
}

\author{
C. LEROUX ${ }^{1,2}$, L. BERNARD ${ }^{1,2}$, F. DESSAUGE ${ }^{3,4}$, F. LE PROVOST ${ }^{5,6}$, P. MARTIN ${ }^{5,6}$ \\ ${ }^{1}$ INRA, UMR1213 Herbivores, F-63122 Saint-Genès-Champanelle, France \\ ${ }^{2}$ Clermont Université, VetAgro Sup, UMR1213 Herbivores, BP 10448, F-63000 Clermont-Ferrand, France \\ 3 INRA, UMR 1348 PEGASE, F-35590 Saint-Gilles, France \\ 4 Agrocampus Ouest, UMR1348 PEGASE, F-35000 Rennes, France \\ ${ }^{5}$ INRA, UMR1313 GABI, F-78352 Jouy-en-Josas, France \\ ${ }^{6}$ AgroParisTech, UMR1313 GABI, F-75231 Paris, France \\ Courriel : christine.leroux@clermont.inra.fr
}

\begin{abstract}
La lactation est contrôlée par de nombreux gènes dont l'expression varie selon différents facteurs, notamment, génétiques et nutritionnels. Ces dernières décennies ont vu l'émergence des études en « omiques » qui permettent de dévoiler une partie des mécanismes moléculaires impliqués dans la biosynthèse et la sécrétion des constituants du lait.
\end{abstract}

Le lait est un fluide biologique extrêmement complexe contenant les constituants nécessaires au développement du mammifère nouveau-né. Des études comparatives de la composition des laits de différentes espèces ont montré que la plupart des laits de mammifères placentaires contient un nombre de composants communs dont les caséines agrégées en micelles, les triglycérides sécrétés sous forme de globules gras, du lactose et du calcium. Cependant, la composition fine varie quantitativement et qualitativement selon les espèces, et est sous l'influence de facteurs génétiques et d'élevage (notamment nutritionnels). Ces différences de composition conditionnent largement les qualités nutritionnelles, sensorielles et technologiques des laits. Or, dans le contexte de pléthore alimentaire que connaît aujourd'hui une partie du monde, l'aliment complet que constitue le lait voit son statut d'élément central de la nutrition quotidienne s'éroder rapidement, notamment du fait de sa composition intrinsèque. En effet, les matières grasses animales, la crème et le beurre, subissent des attaques récurrentes, notamment en raison de leur teneur relativement élevée en Acides Gras (AG) saturés (les produits laitiers fournissent jusqu'à $50 \%$ des graisses saturées consommées par l'Homme) supposés contribuer à l'apparition de certaines pathologies cardio-vasculaires (Astrup et al 2011). Il est donc fondé, sinon essentiel, de se doter d'outils qui permettront de répondre à ces questionnements, sans hypothéquer l'avenir, afin d'adapter la composition du lait aux recommandations nutritionnelles actuelles et à venir, en exploitant une varia- bilité de composition qui peut être obtenue en combinant des leviers génétiques et l'alimentation des ruminants. Aussi, de nos jours, de nombreuses recherches ont pour objectif de préciser les leviers permettant de moduler la composition du lait afin de répondre à la demande de la filière et des consommateurs, ainsi que d'identifier les mécanismes d'action de ces leviers pour en permettre une régulation aussi fine que possible.

L'objet de cet article est de présenter les derniers travaux relatifs aux effets génétiques et nutritionnels, puis de présenter quelques données mettant en lumière les conséquences de leurs interactions sur la biosynthèse et la sécrétion des constituants du lait et plus largement sur le fonctionnement de la glande mammaire étudié au travers de son expression génique. En effet, l'impact de ces facteurs sur la biosynthèse des constituants du lait a, dans un premier temps, été étudié par une approche ciblant les voies métaboliques impliquées, notamment dans la synthèse protéique ou lipidique. Plus récemment l'avènement d'outils d'étude globale (transcriptomique, protéomique) a permis d'ouvrir de nouvelles voies de recherche grâce à l'analyse simultanée de l'expression d'un très grand nombre de gènes, facilitant la compréhension de la physiologie des ruminants laitiers et de la régulation de la lactation. Si les bovins restent bien évidemment le modèle économiquement le plus important, de nombreux travaux sont également conduits chez la chèvre en lactation. Un parallèle entre ces deux espèces sera donc présenté dans cet article de façon à enrichir l'information apportée.

\section{1 / Facteurs génétiques}

\section{1 / L'influence de l'espèce et de la race sur la composition du lait}

Si la nature de ses constituants (principalement eau, protéine, matière grasse, minéraux et lactose) et son apparence sont relativement immuables, la composition fine du lait est en revanche variable. Ainsi, la quantité de protéines totales n'excède pas $10 \mathrm{~g} / \mathrm{L}$ chez certains primates alors qu'elle peut atteindre de 100 à $200 \mathrm{~g} / \mathrm{L}$ chez certains lagomorphes (Martin et al 2003). De même, la quantité de matière grasse est voisine de $15 \mathrm{~g} / \mathrm{L}$ chez les équidés et peut atteindre plus de $150 \mathrm{~g} / \mathrm{L}$ chez les lagomorphes (figure 1). Pour ce qui concerne les espèces d'élevage notons que les laits de vache (Bos taurus), de brebis (Ovis aries) et de chèvre (Capra hircus) contiennent en moyenne respectivement 3,4, 6,1 et $2,9 \%$ de protéines totales (Martin et al 2003) et 3,8, 7,0 et 3,5\% de matière grasse totale. Au delà de cette variabilité inter-espèces, des exemples de variabilité intra-espèce en relation avec l'existence de polymorphismes génétiques sont maintenant relativement bien décrits, particulièrement chez la vache et la chèvre. En revanche, la bibliographie concernant l'effet de ces polymorphismes sur le fonctionnement mammaire, analysé via l'établissement de profils globaux d'expression génique, est relativement peu documentée chez les ruminants. L'objet des paragraphes suivants n'est pas de dresser un catalogue exhaustif des données dans ce domaine, mais de fournir quelques exemples démonstratifs. 
Figure 1. Comparaison des taux butyreux et protéiques selon les espèces (adapté de Martin et al 2003).

Les parties rose clair et foncé correspondent respectivement aux taux butyreux et taux protéiques. Les chiffres mentionnés sont des moyennes en g/L.

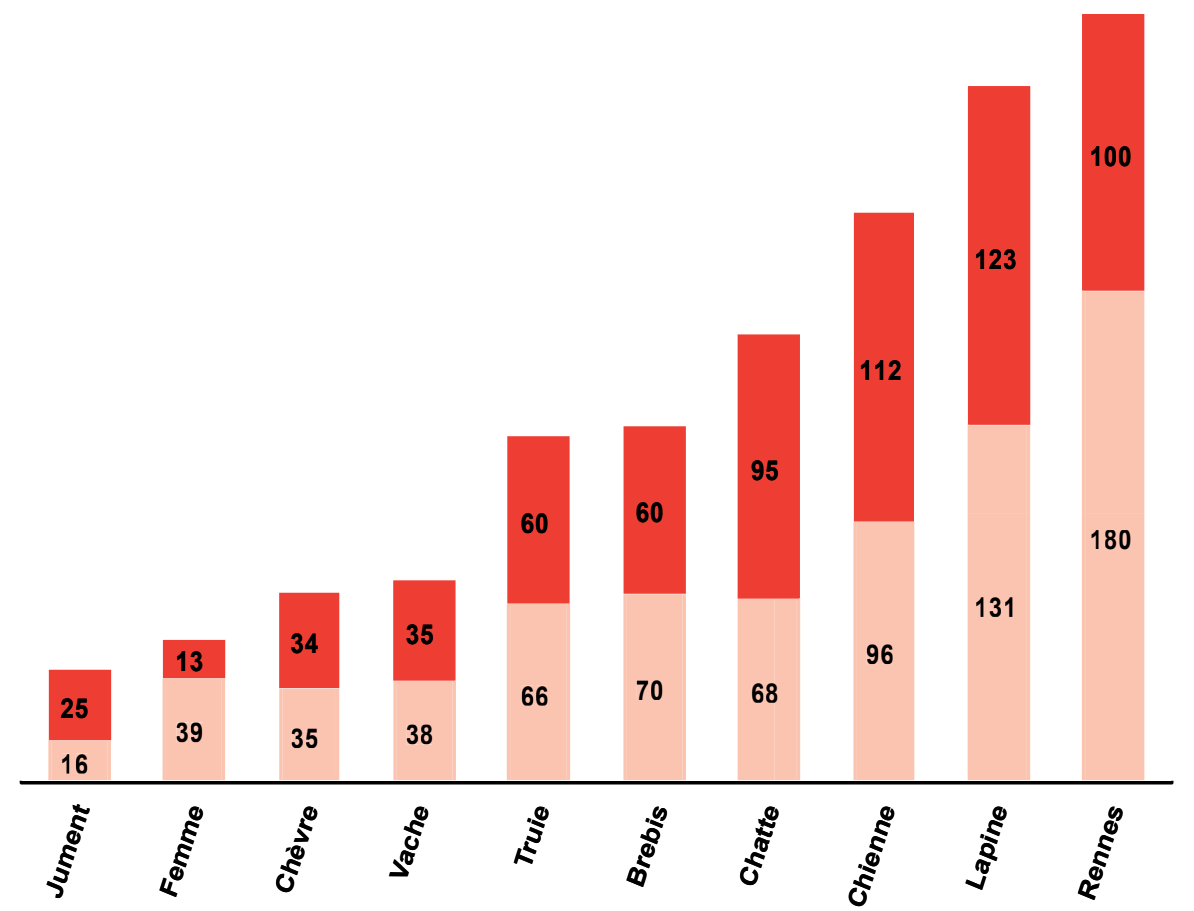

Lipides

Protéines

1.2 / Un des premiers exemples décrit dans la littérature chez les ruminants : l'impact du polymorphisme au locus spécifiant la caséine $\alpha 1$ sur la biosynthèse des constituants du lait et le fonctionnement de la glande mammaire

Les 6 protéines majeures du lait des ruminants sont 2 protéines solubles (ou protéines du lactosérum) : l' $\alpha$-lactalbumine, la $\beta$-lactoglobuline et 4 protéines coagulables : les caséines $\alpha \mathrm{s} 1, \alpha \mathrm{s} 2, \beta$ et $\kappa$. Les rendements fromagers sont largement conditionnés par ces dernières; or, il existe des variations quantitatives et qualitatives imputables aux polymorphismes des gènes les spécifiant. Ainsi chez la chèvre, le locus CSN1S1 spécifiant l'une de ces lactoprotéines (la caséine as1) est particulièrement polymorphe (Grosclaude et al 1994) et présente une grande variabilité d'expression conduisant à une synthèse comprise entre $7 \mathrm{~g} / \mathrm{L}$ (chez un individu porteur de 2 allèles dits forts) à $0 \mathrm{~g} / \mathrm{L}$ (chez les porteurs de 2 allèles dits nuls), avec des situations intermédiaires pour les individus homozygotes porteurs des allèles dits faibles ou intermédiaires, respectivement $F$ et $E$ allant de 0,6 à 1,5 g/L. De plus, une corrélation positive entre le Taux Protéique (TP) et le Taux Butyreux (TB) a été montrée (Grosclaude et al
1994), de sorte qu'une sélection en faveur des allèles forts (taux élevé de caséine) entraîne quasi systématiquement une augmentation du TB des laits de chèvre. Par ailleurs, Chanat et al (1999) ont montré l'existence d'un engorgement du réticulum endoplasmique dû à une accumulation de protéines dans les cellules épithéliales mammaires d'animaux homozygotes pour un allèle CSN1S1 dit défectif (associé à un taux de synthèse réduit de caséine $\alpha s 1$ ).

Pour décrypter les mécanismes sousjacents à ces effets associés au polymorphisme du locus CSN1S1, nous avons tiré profit du développement des outils d'analyse globale d'expression génique que sont les puces à $\mathrm{ADN}$ qui permettent d'évaluer les quantités d'une large part des ARN messagers présents (ou transcriptome). La comparaison du profil d'expression dans la glande mammaire de chèvres homozygotes au locus CSN1S1 allèles forts (référence) avec celui de chèvres porteuses de 2 allèles défectifs a permis d'identifier 5 gènes impliqués dans le métabolisme lipidique (figure 2) parmi les gènes différentiellement exprimés (Ollier et al 2008). En particulier, la sous-expression, dans la glande mammaire des animaux « défectifs » du gène FASN spécifiant la synthétase des acides gras, impliquée dans la synthèse de novo, est en accord avec des résultats antérieurs rapportant une moindre teneur en $\mathrm{AG}$ à chaîne moyenne dans le lait des animaux porteurs d'allèles défectifs au locus CSN1S1 (Chilliard et al 2006). La réduction d'expression des gènes $F A S N$ et GPAM (spécifiant la glycérol phosphate acyltransférase ou GPAT, l'une des enzymes de la voie de synthèse des triglycérides) suggère que le faible taux de matières grasses dans le lait associé à la synthèse réduite de caséine $\alpha s 1$ est pour partie lié à une moindre synthèse d'enzymes clés de la lipogenèse mammaire. De plus, ces travaux ont mis en évidence chez les chèvres « défectives » une moindre expression des gènes $S C D 1$ (spécifiant la stéaroyl coA désaturase ou SCD) qui permet la désaturation en position 9 des $A G$ et conduit notamment à la synthèse de l'isomère majoritaire de l'acide linoléique conjugué ou CLA C18:2 cis9-trans11. Le même constat a été fait avec le gène CYB5R3 qui spécifie la NADH-cytochrome b5 réductase, également impliquée dans la désaturation des $A G$ en position $\Delta-9$. Néanmoins, ces résultats ne sont pas en accord avec une étude portant sur un plus grand nombre d'animaux qui a montré que la proportion d'AG désaturés en position $\Delta-9$ par rapport à leurs homologues saturés était plus importante chez les animaux « défectifs » (Chilliard et al 2006). Cependant, une autre fonction de ce complexe enzymatique est de réguler la fluidité des membranes biologiques qui joue un rôle essentiel dans le métabolisme cellulaire, via la modification de la composition en AG des phospholipides membranaires. Les hypothèses d'un rôle primordial de ce complexe enzymatique dans la fluidité membranaire ou d'une voie alternative de désaturation des AG impliquant une autre désaturase (SCD5), nouvellement identifiée chez les bovins (Lengi et Corl 2007), peuvent rendre compte de ces discordances, et posent ainsi de nouvelles questions de recherche. De plus, notre étude a permis de montrer une altération de l'expression de gènes impliqués dans d'autres voies métaboliques tels que les gènes codant les protéines tyrosine kinases Fer et Fyn, impliquées dans la régulation des interactions cellule-cellule ou encore une modification de l'expression de trois gènes (TFDP2, POLD3 et $T L K 1)$ impliqués dans la synthèse de 1'ADN (figure 2). Ces derniers résultats sont en accord avec une étude antérieure menée en utilisant une membrane pilote (macroarray MEM, développée dans le cadre du programme ROGER d'Agenae), qui a permis d'identifier des gènes différentiellement exprimés, impliqués dans la réparation de l'ADN, selon le génotype (Leroux et al 2003).

Plus récemment, une étude similaire, réalisée dans le cadre du programme « Genomilk Fat » (Programme ANR-ApisGene, Genanimal 2005), a permis, en com- 
Figure 2. Effet du polymorphisme au locus CSN1S1 sur l'expression génique mammaire et sur les altérations biologiques associées (d'après Ollier et al 2008). Représentation schématique d'une cellule épithéliale mammaire de chèvre homozygote pour un allèle " défectif ». Les ratios d'expression et le sens de la régulation sont mentionnés à côté des symboles des gènes identifiés.

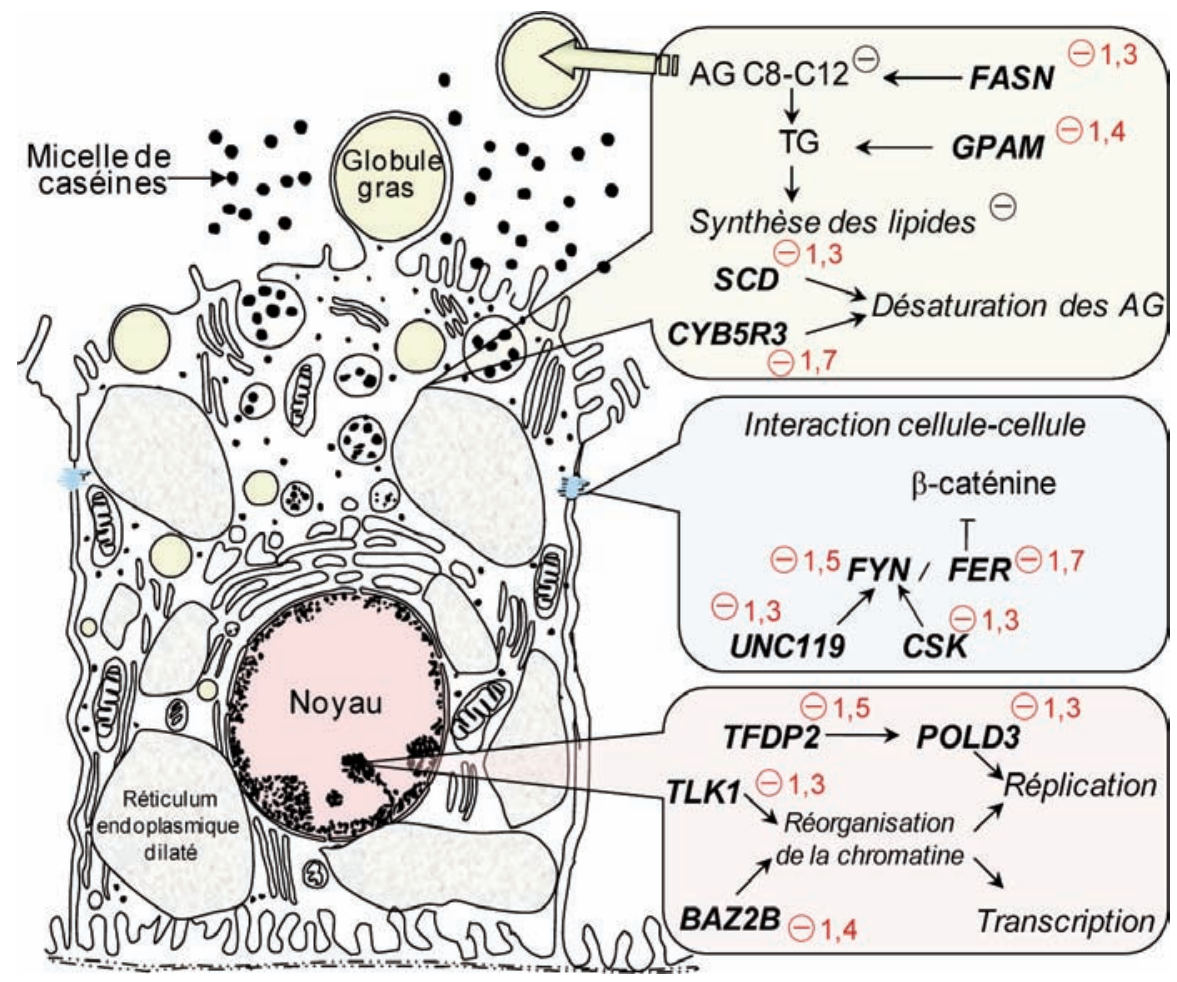

parant cette fois les génotypes les plus extrêmes (CSN1S1A/A vs CSN1S1O/O), d'apporter un éclairage plus précis sur les conséquences de l'accumulation de caséines dans le Réticulum Endoplasmique (RE), en termes de dysfonctionnement de la cellule épithéliale mammaire et d'impact sur la composition du lait. Des analyses protéomiques combinant l'électrophorèse bidimensionnelle, la spectrométrie de masse et la microdissection laser sur des cellules épithéliales mammaires (Bevilacqua et al 2010) ont confirmé les résultats de Chanat et al (1999) et ont apporté la démonstration, en imagerie-MALDI, que les caséines s'accumulent bien dans le RE, alors qu'elles n'ont pas encore été phosphorylées (Beauvallet et al 2008). Cette même étude a également permis de montrer par analyse protéomique différentielle multiplexée (2D-DIGE) que les mécanismes de sécrétion de la cellule épithéliale sont différents chez les chèvres $O / O$ avec la présence dans le lait de celles-ci, de protéines chaperonnes, résidentes du RE (BiP, PDI et GRP94, notamment). Il a, par ailleurs, été démontré que les propriétés physico-chimiques et la composition (lipides polaires et protéines) de la membrane du globule gras étaient également fonction du génotype au locus CSN1S1 (Cebo et al 2012). Enfin, une analyse comparée des profils d'expression génique (en utilisant cette fois une puce ADN bovine plus complète : $22 \mathrm{~K}$ et des animaux extrêmes) a mis en évi- dence 135 gènes présentant une expression différentielle entre génotypes $A / A$ et $O / O$. Bon nombre d'entre eux sont impliqués dans le trafic vésiculaire et la réponse UPR (« unfolded protein response ») consécutive à un stress du RE très probablement induit par l'accumulation de caséines mal conformées ou mal assemblées (Badaoui et al non publié). Ces résultats sont en accord avec ceux issus d'une analyse comparée des profils protéiques des membranes microsomales (Lahouassa et al 2009).

Ces résultats ouvrent donc de nouvelles pistes de recherche sur différentes modifications structurales et fonctionnelles des cellules mammaires, associées au dysfonctionnement du transport cellulaire décrit chez les chèvres déficientes en caséine $\alpha$ s 1, pouvant affecter le fonctionnement de leur glande mammaire et in fine modifier de façon importante la composition et les propriétés technofonctionnelles des laits caprins.

\section{3 / Un exemple, chez les bovins, de l'effet du polymorphisme d'un gène impliqué dans le métabo- lisme des lipides : DGAT1}

Dès le début des années 2000, une double mutation (GC/AA) dans la séquence du gène spécifiant la diacylglycérol acyltransferase 1 (DGAT1) et conduisant à la substitution d'un résidu Alanine (A) par un résidu Lysine (K) en position 232 de la chaîne peptidique (K232A) de cette enzyme, qui catalyse l'ultime étape de la synthèse des triglycérides par addition du troisième et dernier AG sur une molécule de diacylglycérol, a été identifiée comme étant responsable de la forte réduction du TB, et à un degré moindre du TP, observée chez les animaux porteurs de l'allèle « K232 » (Grisart et al 2002, Winter et al 2002). L'hypothèse selon laquelle la mutation K232A est la mutation causale d'un QTL identifié antérieurement portant sur la production et le TB les races Holstein, Normande et Montbéliarde, a été validée (Boichard et al 2003). La forte réduction du TB serait la conséquence d'une perte d'efficacité catalytique de l'enzyme (Grisart et al 2004). Cette mutation induirait également une modification de la composition en $\mathrm{AG}$ du lait qui pourrait traduire une modification de la spécificité de l'enzyme (Schennink et al 2007).

Pour évaluer les conséquences de cette mutation et caractériser les mécanismes moléculaires responsables des phénotypes observés, et par conséquent les gènes affectés dans leur expression par cette mutation, la comparaison du transcriptome mammaire d'individus de génotypes extrêmes, à partir d'un dispositif expérimental génétiquement bien défini et contrôlé a été entreprise. A chaque animal de génotype A232 homozygote associé à un «TB faible», correspondait soit sa pleine sœur $(\mathrm{n}=4)$, soit sa demi-sœur $(n=2)$ de génotype K232 homozygote, associé à un « TB fort ", au même numéro et au même stade de lactation.

L'analyse phénotypique des laits a confirmé une baisse significative du TB $(41,6$ vs $51,6 \mathrm{~g} / \mathrm{kg})$ ainsi qu'une altération du profil des $\mathrm{AG}$ : baisse de la teneur en $\mathrm{AG}$ à chaîne moyenne et insaturée (C14:1 et C16:1) et augmentation des AG à chaîne moyenne et saturée (C14:0) ainsi qu'à chaine longue et insaturée (C18:1 cis11, C18:1 cis 12 , C18:2 n-6, C18:3 n-3) avec le variant «TB faible » (A232), par comparaison au variant « TB fort » (K232). Les globules gras étaient également en moyenne plus petits avec ce variant. L'analyse comparée du transcriptome de biopsies de tissu mammaire, au moyen de 2 répertoires de sondes géniques différents (lames bovines $22 \mathrm{~K}$ du Centre de Ressources Biologiques de Jouy-enJosas et lames commerciales Agilent $4 \mathrm{x} 44 \mathrm{~K})$ a révélé 1496 gènes présentant une expression différentielle $(p<0.1)$. Parmi les gènes surexprimés chez les individus de génotype homozygote A232, associé à un TB faible, figuraient des gènes spécifiant les acteurs des voies de biosynthèse du lactose, des lactoprotéines, et de façon plus surprenante, des gènes impliqués dans le métabolisme 
des lipides, incluant des gènes impliqués dans leur captation ( $L P L, C D 36$ par exemple), leur synthèse ( $A C A C A$ ) et leur transport $(F A B P-3,-4)$, ainsi que des gènes impliqués dans leur sécrétion (BTN1A1, $M U C 1)$. La liste des gènes de la voie de biosynthèse des lipides surexprimés chez les individus de ce génotype explique en revanche, pour partie, les différences de composition en AG observées et suggère que des voies alternatives du métabolisme du diacylglycérol, précurseur principal des triglycérides, mettant en jeu l'enzyme DGAT2, seraient utilisées (Faucon et al 2008). Ces résultats doivent être confirmés et les processus impliquant l'enzyme DGAT2 approfondis.

\section{2 / La régulation nutrition- nelle}

L'alimentation constitue un levier d'action rapide et réversible, pour moduler la quantité et la composition du lait. Il ne s'agit pas ici de retracer l'ensemble des nombreux travaux décrivant les effets de l'alimentation sur la composition du lait (cf. Ferlay et al 2013 ce numéro), mais plutôt de présenter les résultats de travaux conduits au cours de la dernière décennie ayant pour objectif de décrypter les mécanismes moléculaires responsables des modifications de la composition du lait en réponse au facteur nutritionnel.

\section{1 / Effet du niveau d'alimenta- tion sur le fonctionnement de la glande mammaire}

La fonction de lactation est directement dépendante de l'approvisionnement de la glande mammaire en nutriments nécessaires à la synthèse du lait. Une sousalimentation sévère ou de trop longue durée s'accompagne d'une diminution rapide du niveau de production laitière (Chilliard et al 1998). Des travaux récents

Encadré. Nutrigénétique et nutrigénomique.

L'objectif de la nutrigénétique et de la nutrigénomique est de mieux connaître et de comprendre les mécanismes par lesquels l'alimentation et le génome interagissent. Bien que leur objectif in fine soit similaire, ces deux disciplines se distinguent l'une de l'autre par leur approche.

En effet, les études de nutrigénétique et celles de nutrigénomique sont définies, respectivement, d'une part comme l'étude des effets des variations génétiques sur la réponse à l'alimentation et, d'autre part, comme l'étude des effets de l'alimentation sur l'expression génique.

Les deux disciplines utilisent des approches globales dites en « omiques » (Mutch et al 2005, Fenech et al 2011).

chez la vache laitière ont montré qu'une restriction alimentaire sans concentré (60\% herbe et $40 \%$ foin) pendant 11 semaines conduit à une diminution de la production laitière chez les vaches restreintes comparativement aux vaches contrôles, qui produisent 20,5 vs 33,5 L/j (Dessauge et al 2011). Ceci s'accompagne d'une diminution du poids de la glande mammaire $(16,7$ vs $26,9 \mathrm{~kg})$, de la quantité d'ADN total (42 vs $52 \mathrm{mg}$ ) dans la mamelle, de la taille des alvéoles (- 41\%), mais aussi d'une augmentation de la mort des cellules épithéliales mammaires $(0,3$ vs $0,14 \%)$ et d'un remodelage du tissu mammaire (figure 3 ). Enfin, la restriction alimentaire diminuerait l'activité de synthèse des cellules épithéliales. De plus, elle provoque une diminution des concentrations plasmatiques d'IGF-1 («Insulin-like Growth factor $1 »)$ et une augmentation des concentrations d'hormone de croissance (« Growth Hormone », GH).

Alors que ces travaux chez la vache laitière ne montrent pas d'altération du taux butyreux par la restriction alimentaire de longue durée, une privation d'alimentation pendant $48 \mathrm{~h}$ chez la chèvre laitière, conduit à une diminution de la production de lait qui s'accompagne d'une diminution de la sécré-

Figure 3. Effet d'une restriction alimentaire sur la morphologie (coloration hématoxyline-éosine sur coupes congelées) du tissu mammaire après 11 semaines de lactation chez des vaches laitières normalement nourries (55\% ensilage de maïs, $15 \%$ luzerne et $30 \%$ de concentré ; à gauche) et des vaches restreintes (60\% ensilage d'herbe, 40\% foin ; à droite) (d'après Dessauge et al 2011).

Régime contrôle

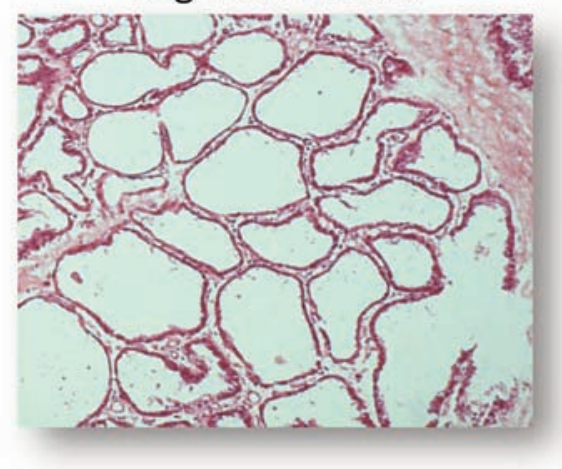

\section{Régime restreint}

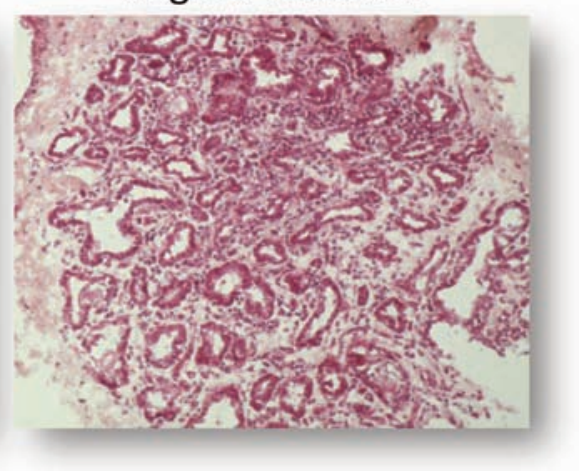

tion de matières grasses dans le lait et d'une modification de sa composition en AG (Massart-Leen et Peeters 1985). Aussi, pour la première étude de nutrigénomique (cf. encadré), qui visait à valider l'utilisation de ces études dites en " omiques » au niveau mammaire et de leur mise en relation avec la sécrétion et la composition du lait, nous avons utilisé un modèle de restriction alimentaire sévère chez des chèvres en lactation. Pour ce faire, les transcriptomes mammaires de chèvres en lactation réparties en deux lots (un lot alimenté de façon à couvrir les besoins des chèvres et un lot privé d'alimentation pendant 48 heures) ont été comparés à l'aide d'une puce à $\mathrm{ADN}$ représentant 8379 gènes $(8,4 \mathrm{~K})$. Cette étude a montré qu'une non-alimentation de $48 \mathrm{~h}$ chez des chèvres en lactation altère l'expression d'au moins 161 gènes dans la glande mammaire, en plus de modifier la production et la composition du lait (Ollier et al 2007). La grande majorité de ces gènes $(88 \%)$ étaient sous exprimés chez les chèvres privées d'alimentation par rapport aux chèvres contrôles, suggérant une diminution de l'activité transcriptionnelle de la glande mammaire qui pourrait contribuer, avec le manque d'approvisionnement en nutriments, à la diminution de la production de lait et de la sécrétion de ses constituants. En effet, la moindre quantité de protéines sécrétées dans le lait des chèvres non alimentées peut être reliée à la diminution d'expression de 5 des 6 gènes codant les lactoprotéines majeures (les 2 principales protéines solubles $L A L B A$ et $L G B$ et 3 des 4 caséines : $C S N 1 S 1, C S N 1 S 2, C S N 2)$. De même, la sous-expression du gène spécifiant l' $\alpha$-lactalbumine ( $L A L B A)$, impliquée dans la synthèse du lactose, est en accord avec la chute de la sécrétion de lactose dans le lait des chèvres non alimentées, elle-même en partie responsable de la chute de la production laitière. Enfin, la moindre biosynthèse de matières grasses, et en particulier des AG à chaînes courtes et moyennes présentes dans le lait des chèvres non alimentées, peut être associée à la sousexpression du gène $F A S N$ impliqué dans la synthèse de novo des AG. De plus, 
l'expression de 2 autres gènes impliqués dans le métabolisme lipidique, $A C S B G 1$ et $A Z G P 1$, paraît également être régulée par le statut nutritionnel. Le rôle des protéines codées par ces 2 gènes, respectivement la lipidosine et la zinc- $\alpha 2$ glycoprotéine, n'avait pas encore été décrit dans la glande mammaire. Cependant, ces gènes sont décrits pour spécifier des protéines impliquées, respectivement dans la lipomobilisation au sein des tissus adipeux (Bao et al 2005) et dans l'activation des $\mathrm{AG}$ à longue chaîne (Steinberg et al 2000). Ainsi, ces deux gènes constituent de nouveaux candidats pour étudier les mécanismes contrôlant la composition de la matière grasse laitière en réponse à des facteurs alimentaires. Par ailleurs, cette étude a aussi révélé une sous-expression de gènes impliqués dans la différenciation ou la prolifération cellulaire, et une modification de l'expression de gènes impliqués dans la mort cellulaire programmée, à la fois par apoptose et par autophagie, dans la glande mammaire des chèvres privées d'alimentation. Or, l'involution de la glande mammaire se caractérise par une dédifférenciation et une disparition des cellules épithéliales mammaires par apoptose. Mais, quelques études menées chez les rongeurs et très récemment chez les bovins suggèrent que ce processus d'apoptose s'accompagne d'un mécanisme d'autophagie (Gajewska et al 2005). Ainsi, notre étude a mis en évidence des gènes impliqués dans ces 2 programmes de mort cellulaire. La modification de leur expression en réponse à la non-alimentation pourrait être responsable d'une orientation de la glande mammaire vers un processus précoce d'involution qui constitue une piste d'investigation intéressante pour étudier cette phase particulière des cycles de production (gestation/lactation), spécifique de la glande mammaire.

\section{2 / Effet de la nature du four- rage et de la supplémentation lipidique sur la biosynthèse et la sécrétion des constituants du lait}

L'alimentation, en particulier la supplémentation lipidique et ses interactions avec les fourrages et les concentrés amylacés, module tout particulièrement la quantité et la composition des matières grasses laitières (Bauman et Griinari 2000, Chilliard et al 2001). Les AG des triglycérides du lait ont une double origine. Ils proviennent soit d'une synthèse de novo (environ 40 à $60 \%$ ) dans le cytoplasme de la cellule épithéliale mammaire, soit du plasma. La synthèse de novo conduit à la synthèse des $\mathrm{AG}$ à chaînes courtes et moyennes (C4 à C16) et s'effectue essentiellement à partir de l'acétate et du $\beta$-hydroxybutyrate. Les $A G$ à longue chaîne (C18 et plus) et une partie des C16 proviennent, quant à eux,
Figure 4. Les enzymes clés de la lipogenèse et synthèse de la matière grasse dans la cellule épithéliale mammaire du ruminant (d'après Ollier et al 2007).

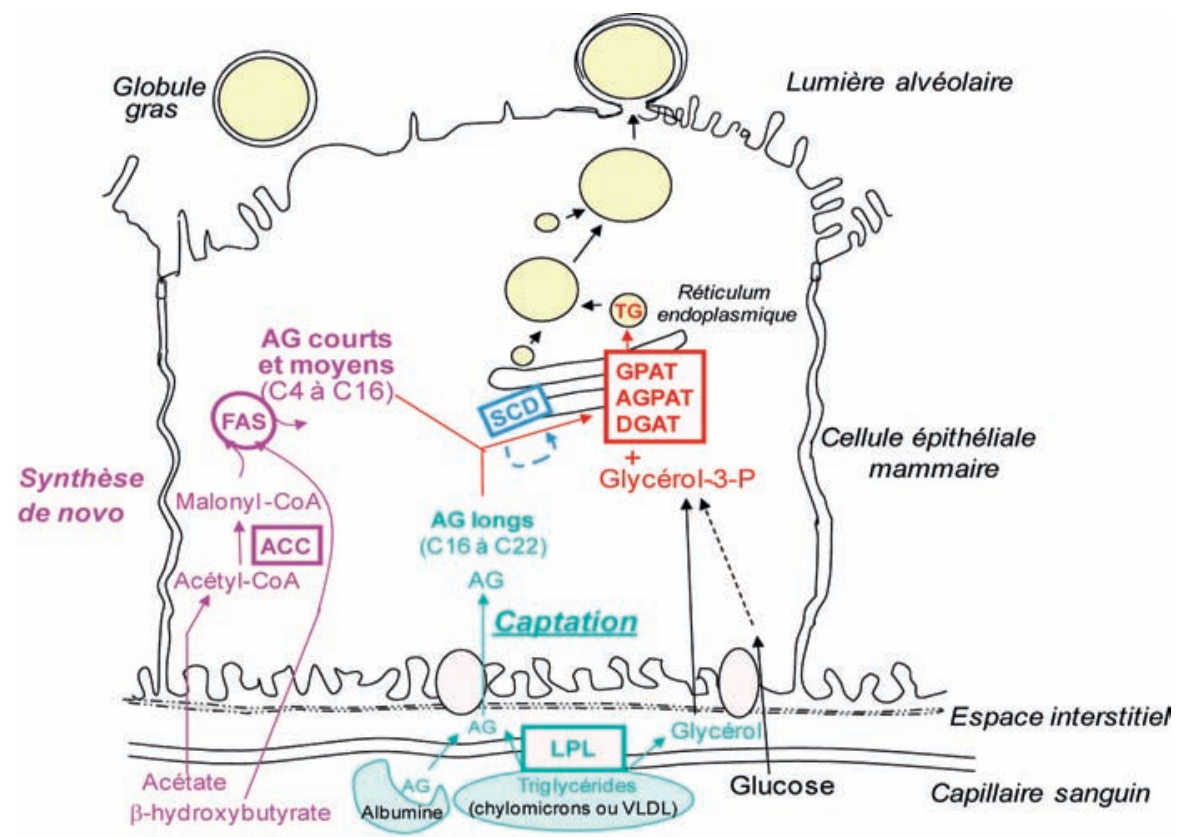

GPAT: Glycérol-3-phosphate acyltransférase

LPL : Lipoprotéine-lipase

SCD : Stéaroyl-CoA désaturase

TG : Triglycérides

\section{AGPAT: Acylglycérol-3-phosphate acyltransférase}

du captage des AG circulant qui sont issus principalement de l'alimentation (origine exogène) et de la mobilisation des tissus adipeux (importante quand l'animal est en bilan énergétique négatif). Dans leur ensemble, ces AG, peuvent être désaturés au niveau du réticulum endoplasmique où ils sont ensuite estérifiés au glycérol lors de la synthèse des triglycérides qui sont ensuite sécrétés sous forme de gouttelettes lipidiques.

a) La régulation nutritionnelle de la lipogenèse mammaire : les approches ciblées

La biosynthèse de la matière grasse du lait fait intervenir de nombreuses enzymes dont les principales ont fait l'objet d'études de leur expression dans la glande mammaire depuis une dizaine d'années. Ainsi, des études ciblées ont été réalisées sur les enzymes clés de la lipogenèse (figure 4) : l'acétyl coA carboxylase (ACC spécifiée par le gène $A C A C A$ ), la synthétase des acides gras (FAS spécifiée par le gène $F A S N$ ) toutes deux impliquées dans la synthèse de novo des acides gras à chaines courte et moyenne du lait ainsi que la lipoprotéine lipase (LPL) et la stéaroyl coA désaturase (SCD), respectivement responsables de la captation des AG longs des triglycérides et de la désaturation en position 9 des AG. Ces études ont eu pour objet de mesurer l'activité de ces enzymes ou de quantifier leur ARNm.
Les premières études menées pour décrypter les mécanismes moléculaires de la régulation nutritionnelle de la lipogenèse mammaire ont été conduites chez la vache laitière recevant des régimes connus pour induire une réduction importante de la synthèse et de la sécrétion des matières grasses du lait (régime conduisant à une " milk fat depression » ou MFD). Ces études ont montré que les régimes riches en concentrés (Peterson et al 2003), avec de l'huile de soja (Piperova et al 2000), de l'huile de poisson (Ahnadi et al 2002), des huiles végétales et marines (Harvatine et Bauman 2006, Angulo et al 2012), et des infusions post-ruminales ou intraveineuses de trans-10,cis-12-CLA (Baumgard et al 2000, Harvatine et Bauman 2006, Gervais et al 2009), ont un effet MFD chez la vache et conduisent à une forte diminution de la sécrétion des $A G$ à chaîne moyenne (- 30 à - 59\% de C10 à C16) dans le lait. Cette diminution a été associée à celle de l'expression (ARNm et/ou activité enzymatique) des gènes $A C A C A$ et $F A S N$. Peterson et al (2003) ont montré que cette réduction d'expression touche également les gènes spécifiant la glycérol phosphate acyltransférase (GPAT) et l'acylglycérol phosphate acyltransférase (AGPAT) impliquées dans la synthèse des triglycérides. Ensuite, le panel de gènes étudiés a été élargi à l'étude des gènes spécifiant les facteurs de régulation de 
l'expression des gènes de la lipogenèse que sont SREBPF1 (« sterol regulatory element binding transcription factor $1 »)$, INSIG1 (« insulin induced gene $1 »$ ) et S14. Ces facteurs de transcription font également l'objet d'une diminution de leur expression suite à un régime MFD (Harvatine et Bauman 2006, Gervais et al 2009, Angulo et al 2012). Ces dernières années le nombre de gènes étudiés par une approche ciblée s'est encore accru jusqu'à plusieurs dizaines. Ainsi, des réseaux de régulations du métabolisme des lipides dans la glande mammaire ont été mis en évidence in vivo ou in vitro, permettant à Loor et collaborateurs de remettre en question le rôle central de SREBPF1 et de suggérer un rôle crucial d'une action concertée de PPARG («peroxisome proliferator-activated receptor gamma »), PPARGC1A et INSIG1 (Bionaz et Loor 2008, Kadegowda et al 2009).

Des études utilisant le même type d'approche ont été réalisées chez la chèvre en lactation avec des régimes plus proches de ceux utilisés en élevage. Ces études (Bernard et al 2005a,b, 2009a,b, Ollier et al 2009) ont permis de montrer que chacun des principaux gènes « candidats » de la lipogenèse mammaire a une réponse spécifique, moins marquée que celle des sécrétions d'AG du lait correspondants. Ainsi, les régimes supplémentés en huiles végétales qui conduisent à une forte augmentation de la sécrétion des $\mathrm{AG}$ à 18 atomes de carbones $(>100 \%)$ ne s'accompagnent pas de changement de l'abondance du messager et de l'activité enzymatique de la LPL. La disponibilité en substrat semble être plus limitante que le potentiel enzymatique de cette lipase. Ces mêmes régimes conduisent à une diminution de 5 à $32 \%$ de la sécrétion des AG à châ̂ne moyenne sans variation significative de l'abondance du messager et de l'activité enzymatique de l'ACC et de la FAS. En revanche, les variations d'expression du gène $A C A C A$ sont bien corrélées à la sécrétion des $\mathrm{AG}$ à chaîne moyenne (Bernard et al 2008). Par ailleurs, pour la FAS comme pour l'ACC (Bernard et al 2009a), la variation du niveau d'ARNm en réponse à la supplémentation lipidique des rations est corrélée à celle des activités enzymatiques suggérant une régulation au niveau transcriptionnel de ces 2 gènes, en plus de la régulation post-traductionnelle déjà largement décrite pour l'ACC. Enfin, l'expression du gène $S C D 1$ varie peu (Bernard et al 2008) probablement en raison de son implication dans le maintien de la fluidité membranaire. En effet, chez la chèvre une diminution de la teneur en ARNm SCD1 a été observée seulement dans le cas de régimes enrichis en acide linolénique " protégé » (graines de lin formolées). Par ailleurs, le rôle putatif de SCD5
(Lengi et Corl 2007) dans la réponse à la supplémentation lipidique n'est pas à exclure et pourrait rendre compte de la faible variation des transcrits $S C D 1$ lorsque des variations de l'activité enzymatique et/ou des rapports de désaturation dans le lait sont observées.

L'ensemble des résultats des études nutritionnelles réalisées chez la chèvre comparativement à l'ensemble des résultats obtenus chez la vache avec des régimes proches, suggère des spécificités inter-espèces du métabolisme des lipides dans le rumen et de la glande mammaire. Les caprins, contrairement à ce qui est observé chez la vache, ont probablement une plus grande stabilité du métabolisme ruminal (en faveur de la biohydrogénation des AG via la voie des trans-11 au détriment de la voie des trans-10, Bernard et al 2009a), avec des biohydrogénations ruminales moins complètes ; ceci pourrait être lié à des différences du microbiote ruminal (non documenté pour l'instant) et/ou à un comportement alimentaire différent entre ces 2 espèces. Par ailleurs, de récentes études suggèrent que la lipogenèse mammaire chez la chèvre est moins sensible aux effets antilipogéniques du trans-10,cis-12-CLA (de Andrade et Schmidely 2006, Lock et al 2008, Shingfield et al 2009). Les études réalisées chez la chèvre (Bernard et al 2008) ont également souligné le rôle primordial de la nature et de la quantité des substrats disponibles pour la mamelle. Ainsi, une première étude, chez la chèvre, visant à définir le devenir métabolique dans la glande mammaire de l'Acide Vaccénique (AV) (captation, conversion en Acide Ruménique (AR) dans la mamelle, apparition de AV et AR dans le lait) a montré grâce à l'utilisation de l'isotope stable ${ }^{13} \mathrm{C}$-trans-1118:1, délivré par voie intraveineuse à des chèvres laitières dans des conditions nutritionnelles différentes (régimes à teneurs variables en lipides et en amidon), que la synthèse endogène d'AR dans la glande mammaire est la principale source de cet $A G$ dans la matière grasse laitière, avec 63 à $73 \%$ de l'AR qui provient de la delta-9 désaturation de $32 \%$ de l'AV capté (Bernard et al 2010). Ces données sont comparables à celles obtenues chez la vache laitière (64-97\%) avec une méthode comparable (Mosley et al 2006) ou par des estimations à partir des flux digestifs et du lait d'AV et d'AR (Glasser et al 2008) suggérant que la différence inter-espèce ne touche pas l'ensemble du métabolisme lipidique mammaire.

b) Les approches globales de nutrigénomique

Très récemment, des études de nutrigénomique mettant en œuvre une approche globale utilisant des «microarrays » (ou puce à $\mathrm{ADN}$ ) ont été réalisées afin de déterminer l'effet de la supplémentation en différentes huiles végétales (huiles de colza, de soja, de lin ou un mélange de ces 3 types d'huile) apportant des AG insaturés, sur la production laitière et l'expression génique mammaire (Mach et al 2011). Les supplémentations ont eu pour conséquence d'augmenter la production laitière $(+15 \%)$ et de diminuer de plus de $20 \%$ le TB et de plus de $6 \%$ le TP. Ces diminutions peuvent être consécutives à un phénomène de dilution dû à l'augmentation de la production laitière. La composition en AG a également été affectée par la supplémentation, avec une diminution des $A G$ à chaîne courte et moyenne $(41,2$ vs $35,6 \%$, respectivement, pour les régimes contrôles et supplémentés) et une augmentation des AG à chaîne longue. Une analyse transcriptomique réalisée avec une puce bovine Affymetrix a révélé un différentiel d'expression pour 972 gènes suite à la supplémentation lipidique comparativement aux transcriptomes d'animaux ayant reçu un régime contrôle. Parmi les gènes du métabolisme des lipides, plus de la moitié ont une expression diminuée suite à la supplémentation, notamment le gène $A C A C A$ en accord avec la réduction du pourcentage des $A G$ à chaîne courte et moyenne. Nous pouvons également noter une réduction de l'expression du facteur de transcription SREBP1 régulant l'expression de nombreux gènes de la lipogenèse. Parmi les gènes dont l'expression est réduite suite à la supplémentation, se trouvent également ceux impliqués dans le développement et le remodelage cellulaire, dans l'apoptose et la réponse immunitaire (Mach et al 2011). Les auteurs suggèrent que ces altérations de l'expression génique puissent être liées à une modification du fonctionnement de la cellule épithéliale mammaire conduisant à une augmentation de la synthèse du lait.

Une étude similaire a, antérieurement, été réalisée chez la chèvre en utilisant une puce à oligonucléotides longs $(8,4 \mathrm{~K})$ afin de déterminer les effets de rations pauvre ou riche en concentré, supplémentées ou non en lipides, sur la régulation de l'expression génique dans la glande mammaire, en relation avec la composition du lait. La supplémentation lipidique d'un régime riche en fourrage (HF-64: 36) et d'un régime riche en concentré (LF-43:57), respectivement avec 6\% de graine de colza (HF-RS) et de 4\% d'huile de tournesol (LF-SO) affecte la composition en AG dans le lait (Ollier et al 2009). Après 3 semaines de traitement la production laitière s'est avérée être plus faible chez les chèvres ayant reçu le régime HF-RS que chez les chèvres ayant reçu les autres régimes $(3,85$ vs $4,24 \mathrm{~kg} / \mathrm{j})$ et le TB plus fort chez les animaux recevant les régimes supplémentés (HF-RS 
ou LF-SO) comparativement aux animaux recevant les régimes non supplémentés $(38,5$ vs 32,4 g/kg). Enfin la composition en $\mathrm{AG}$ a également été modifiée par la supplémentation qui conduit, notamment, à une forte diminution des C12:0, C14:0 et C16:0. Le régime HF$\mathrm{RS}$, quant à lui, maximise le ratio $18: 3 \mathrm{n}$ 3/18:2n-6 et conduit à une plus forte teneur en acide oléique (22,7 vs 14,6\%). Une classification hiérarchique de teneur en $\mathrm{AG}$ a permis de séparer les régimes HF et LH vs les régimes supplémentés et également de distinguer les régimes HF-RS et LF-SO. De même, la double classification ascendante hiérarchique des profils d'expression génique obtenus suite à l'analyse transcriptomique, a réparti les échantillons selon le régime reçu. Mais cette fois, les 16 échantillons étudiés (4 par régime) l'ont été en 2 groupes principaux correspondant d'une part, aux échantillons issus des chèvres supplémentées et d'autre part à ceux des chèvres non supplémentées. Ces 2 groupes sont eux-mêmes subdivisés en 2 groupes chacun classant, de façon univoque, les échantillons représentant les 4 régimes dans 4 groupes distincts (figure 5).

Figure 5. Classification hiérarchique des profils d'expression génique dans la glande mammaire de chèvre en lactation ayant reçu des régimes riche (HF) ou pauvre (LF) en fourrage et supplémenté ou non avec de l'huile de tournesol (LF-SO) ou de la graine de colza (HF-RS), (d'après Ollier et al 2009).
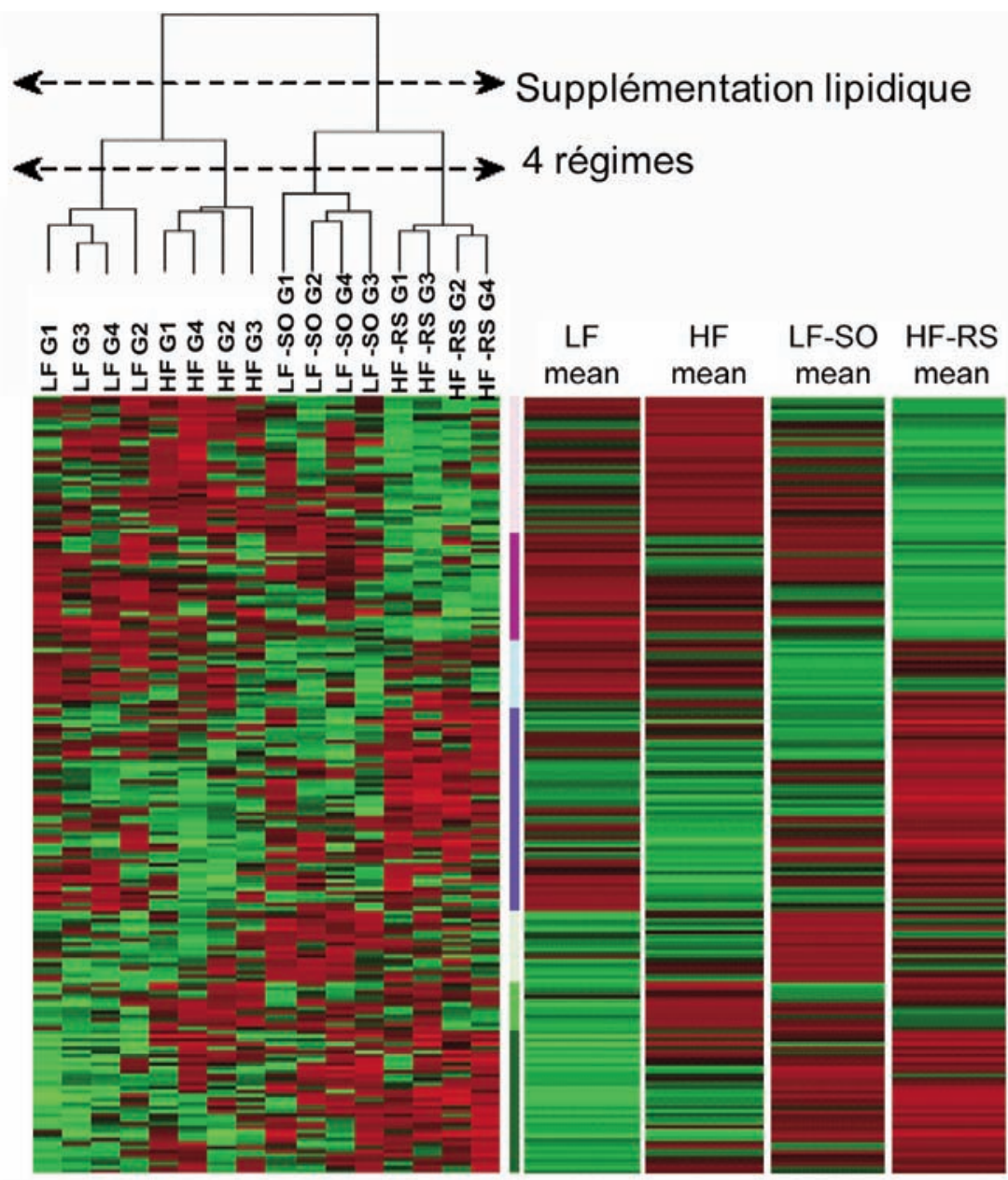

(Pagano et al 2010). Parallèlement, l'étude des effets de la non-alimentation de $48 \mathrm{~h}$ sur le profil d'expression génique chez les chèvres en lactation, complétée par l'étude des effets du polymorphisme du gène CSN1S1, a mis en exergue l'existence d'une interaction entre le niveau d'alimentation et le génotype à ce locus. En effet si les effets du jeûne sur la production laitière et la composition ont été observés quelque soit le génotype, l'amplitude de cette réponse diffère selon le génotype avec, d'une façon générale, une diminution plus élevée chez les chèvres porteuses des allèles dits forts que chez celles porteuses d'allèles dits faibles $(-89 v s-79 \%$ pour la production laitière, $-67 v s-35 \%$ pour la matière grasse, $-82 v s-65 \%$ pour les protéines et - $93 v s-85 \%$ pour le lactose).

De même, la comparaison des profils (ciblés ou globaux) d'expression génique suite à la non-alimentation en fonction du génotype au locus CSN1S1 montre une différence dans l'amplitude de la réponse (figure 6). Ainsi, parmi les 8 ARNm impliqués dans le métabolisme des lipides étudiés, 5 présentent une différence d'abondance chez les chèvres porteuses des allèles forts alors que pour les chèvres défectives seulement 2 de ces 8 gènes sont différentiellement exprimés. De même, la comparaison des transcriptomes mammaires des chèvres alimentées et non-alimentées a mis en évidence 172 gènes (parmi les 8739 présents sur la puce) différentiellement exprimés chez les chèvres porteuses des allèles forts alors que seulement 109 sont différentiels chez les chèvres défectives. L'ensemble de ces résultats montre l'effet plus marqué du niveau d'alimentation chez les animaux porteurs d'allèles associés à un fort taux de synthèse de caséine $\alpha$ s1 (génotype fort) comparativement à ceux porteurs d'allèles dits défectifs. Cependant ces résultats restent à confirmer sur un plus grand nombre d'individus.

\section{2 / De nouveaux mécanismes de régulation de l'expression génique par l'alimentation}

Comme nous venons de le voir, l'environnement et plus particulièrement l'alimentation modifie la régulation de l'expression des gènes. Ces dernières décennies de nouveaux types d' « interrupteurs » ont été identifiés. Ils interviennent via des modifications au niveau de l'ADN, transmissibles d'une génération à l'autre, mais ne touchent pas la séquence elle-même du génome. Ces phénomènes par lesquels l'environnement modifie l'expression génique (appelé épigénétique agissant sous forme d'empreinte) regroupent, par exemple, des modifications telles que les méthylations ou le code des histones. Si ce domaine de recherche, 
Figure 6. Effet de la restriction alimentaire selon le génotype au locus CSN1S1 (allèles forts vs allèles défectifs) sur le transcriptome mammaire de chèvres en lactation (d'après Ollier et al 2006).

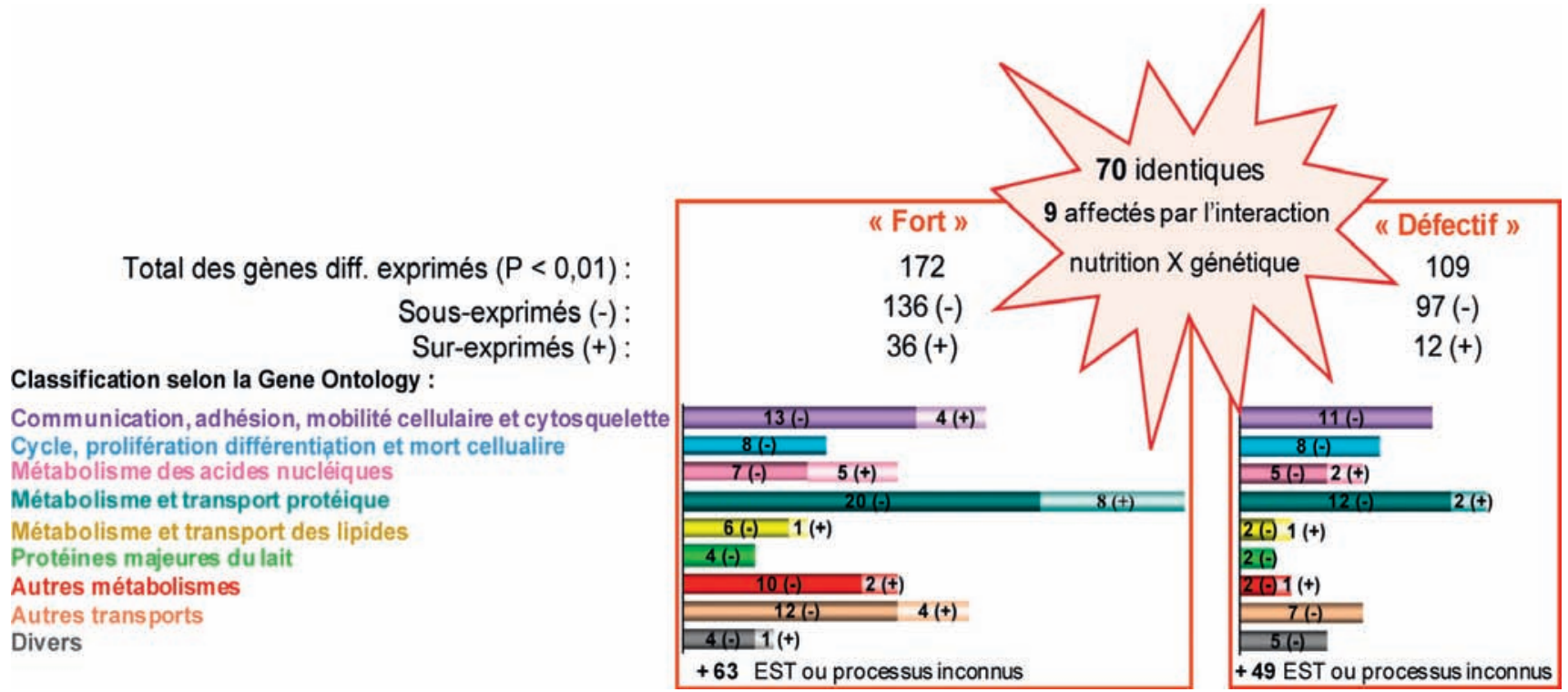

récent chez les animaux d'élevage, est passionnant, il n'en est qu'à ces balbutiements et ne fera pas l'objet d'un développement plus large dans cet article (voir Devinoy et Rijnkels 2010, Singh et al 2010). Outre ces phénomènes, un autre type de régulation de l'expression génique fait intervenir des ARN non codants et plus particulièrement des petits ARN appelés microARN. Depuis le début des années 2000, leur rôle, dans de nombreuses fonctions, voies métaboliques ou pathologies (développement embryonnaire, maintien de cellules souches, métabolisme des acides gras, cancer...), a été décrit notamment chez les rongeurs ou l'Homme. De plus en plus de travaux chez la souris font état d'un rôle des microARN dans la régulation du métabolisme des lipides via leur action directe sur l'expression de gènes de la lipogenèse
(Esau et al 2006, Lynn 2009, Moore et al 2010) et/ou indirectement au travers de la régulation de leurs facteurs de transcription tel que PPAR $\gamma$, SREBP1 et 2 (Lynn 2009, Horie et al 2010, Marquart et al 2010). Ainsi, il a été montré que l'expression d'un microARN (miR-122) joue un rôle très important dans le métabolisme lipidique hépatique en agissant sur des cibles telles que les ARNm de la $F A S N$ ainsi que ceux spécifiant SREBP1 et 2 (facteurs de transcription de gènes de la lipogenèse). De même, l'inhibition de l'expression d'un autre microARN, miR-143, dans le tissu adipeux réduit l'accumulation de triglycérides due à une diminution de l'expression de gènes impliqués dans le métabolisme lipidique tels que $F A B P 4, L I P E$ ainsi que le facteur de transcription PPAR $\gamma$ impliqué dans la régulation de gènes de la lipoge- nèse (Lynn 2009). Cependant, les profils d'expression des microARN ont été étudiés au cours du développement et la différenciation de la glande mammaire ou pendant la lactation, essentiellement chez les rongeurs (Ibarra et al 2007, Wang et Li 2007, Avril-Sassen et al 2009, Sdassi et al 2009, Tanaka et al 2009). Plus récemment le rôle de quelques microARN dans la glande mammaire a été décrit (Greene et al 2010, Ucar et al 2010). De même, nos travaux ont permis de montrer que la sur-expression d'un seul microARN (miR-30b) dans les cellules épithéliales mammaires murines entraîne une diminution de la lactation (Le Guillou et al 2012) et modifie la structure de la glande mammaire (figure 7). Cependant, chez les espèces d'élevage, très peu de données sont disponibles aussi bien du point de vue expressionnel

Figure 7. La surexpression de miR-30b affecte la structure de la glande mammaire pendant la lactation (A) et l'involution (B) (d'après Le Guillou et al 2012).

Analyse histologique (coloration HES) de glande mammaire murine transgéniques ( $\mathrm{Tg}$ ) et en lactation (A, 12 jours) et en involution (B, 6 jours).

A

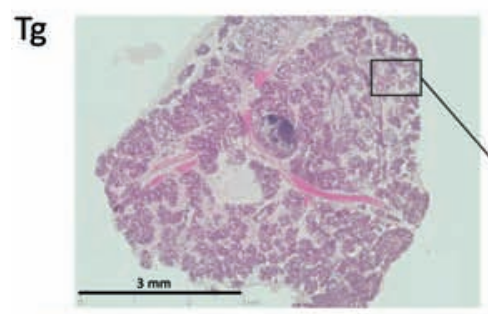

WT

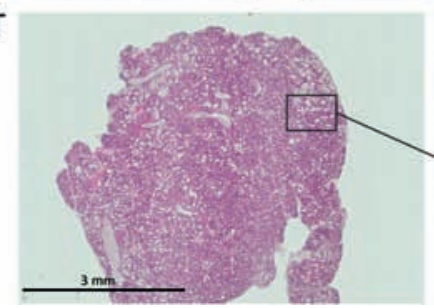

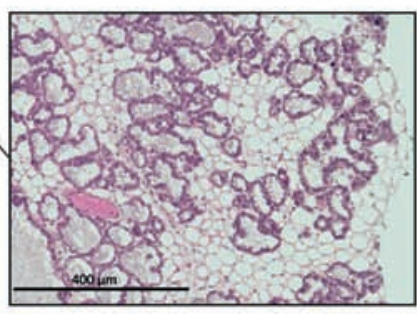

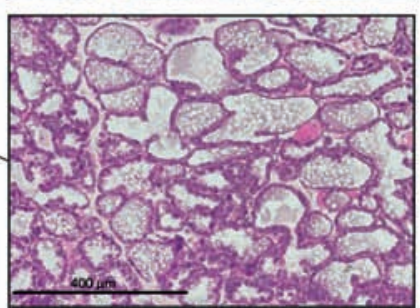

B

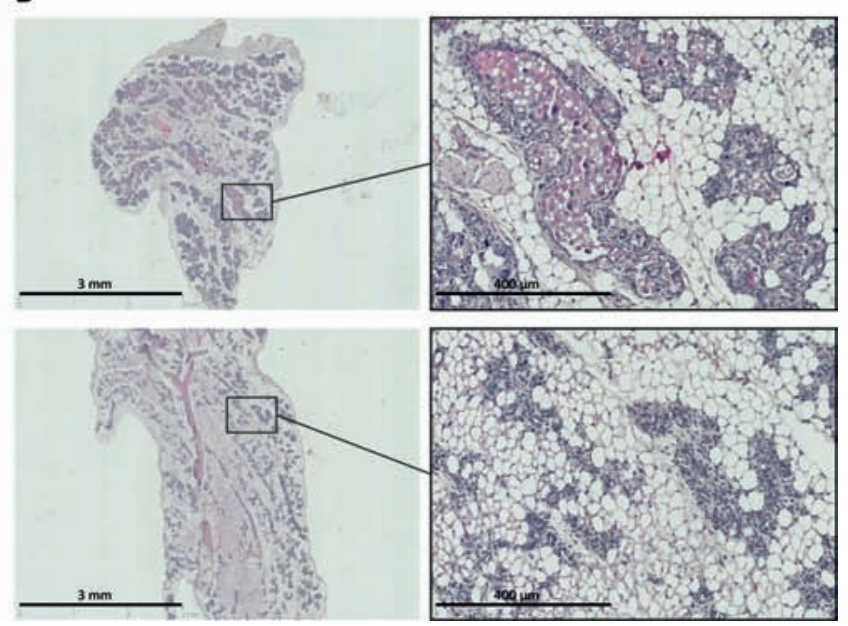


(Gu et al 2007, Le Guillou et al 2012) que fonctionnel. Par exemple, très récemment, des sites potentiels de fixation de microARN ont été détectés dans le locus des gènes des caséines. Un des sites, situé dans le locus de la caséine $\alpha$ s1, est polymorphe dans les races caprines espagnoles étudiées et les auteurs ont suggéré qu'il puisse contribuer à la variabilité d'expression du gène de la caséine $\alpha \mathrm{s} 1$ (Zidi et al 2010). L'ensemble de ces données récentes montre le rôle potentiel de ces microARN dans la cellule épithéliale mammaire. Parallèlement, la régulation nutritionnelle de l'expression des microARN est reconnue, bien qu'elle n'ait été étudiée, là encore, que chez les rongeurs ou l'Homme (Ross et Davis 2011, Milenkovic et al 2012). La relative conservation inter-espèces des mécanismes de régulation des microARN permet l'hypothèse d'une telle régulation nutritionnelle de leur expression ainsi que leur rôle dans le métabolisme des lipides chez les ruminants.

\section{Conclusion-Perspectives}

Les études d'expression génique entreprises au cours des dernières années ont permis d'acquérir de nouvelles connaissances sur le fonctionnement de la glande mammaire et la régulation de la fonction de lactation. Elles ont notamment mis en exergue des gènes impliqués dans la biosynthèse des constituants du lait, dont l'expression était jusqu'à présent inconnue, et permis de suggérer la mise en place de voies métaboliques de « substitution " ouvrant ainsi de nouveaux champs d'investigation. De même, la découverte de voies de régulation mettant en jeu des phénomènes temporaires tel que l'empreinte épigénétique ou encore l'intervention d'ARN non codant, qui contrôle l'expression du génome et dont le rôle dans de nombreux processus biologiques est maintenant reconnu, laissent entrevoir de réelles possibilités d'accéder à une meilleure compréhension des mécanismes complexes qui orchestrent le fonctionnement de la glande mammaire. Enfin, l'accès à de nouveaux outils tels que le séquençage à haut-débit et la génomique à l'échelle de la cellule, en permettra une description encore plus fine et exhaustive. Ainsi, très récemment, l'expression de plus de 16000 gènes a été rapportée dans les cellules somatiques isolées du lait à différents stades de la lactation (Wickramasinghe et al 2012), donnant une description précieuse du « lactome » bovin au cours de la lactation.

Cette complexité s'accrô̂t encore lorsque nous considérons non plus le fonctionnement mammaire isolément, mais en le replaçant dans son environnement, c'est-à-dire lorsque nous prenons en compte ce qui arrive à la mamelle que ce soit en termes de nutriments ou de signaux émanant d'autres tissus tels que les hormones, les métabolites ou même les exosomes. Ces microvésicules secrétées par bon nombre de cellules, contiennent des protéines mais aussi des ARN messagers et des microARN. Elles contribuent à la communication entre cellules et entre tissus. Bien que leur existence soit connue depuis presque 30 ans, ce n'est que depuis la découverte de leur contenu en acides nucléiques que leur structure et leur rôle ont suscité un fort intérêt, y compris dans le domaine des recherches sur le lait (Hata et al 2010, Reinhardt et al 2012). Là encore, la connaissance des mécanismes de communication et de dialogue entre les tissus permettra de mieux comprendre les effets des facteurs nutritionnel et génétique sur le fonctionnement de la glande mammaire, en intégrant leurs effets au niveau de l'animal.

L'un des enjeux de ces prochaines années réside bien en ce changement d'échelle allant du décryptage de mécanismes moléculaires de plus en plus complexes à leur intégration au niveau de l'animal tout en tenant compte des interactions entre les différents facteurs, génétique et nutritionnel, mais aussi certaines pratiques d'élevage (tel que la monotraite, cf. Guinard-Flament et al 2013, ce numéro), modulant la composition du lait. L'intégration de l'ensemble de ces données pourra venir enrichir les modèles de prédiction de réponses des vaches laitières, selon leur mérite génétique, à des alimentations différenciées. Ainsi, une e-cow qui intègre différents algorithmes déjà publiés reposant essentiellement sur des données de performances, vient-elle de voir le jour (Baudracco et al 2012). L'intégration de l'ensemble des données disponibles et à venir sur les mécanismes de régulation et sur le fonctionnement de la glande mammaire dans des modèles de prédiction constitue pour les prochaines années un défi à révéler. Pour ce qui concerne les perspectives des pratiques d'élevage, l'ensemble des données d'expression génique acquises et celles à venir seront un atout complémentaire de la sélection génomique des ruminants laitiers (cf. Brochard et al 2013, ce numéro). De plus, il sera alors possible d'envisager, grâce à une régulation aussi fine que possible, tirer le meilleur parti du potentiel génétique des troupeaux pour fournir, par une alimentation optimisée, des produits différenciés de qualité, tout en tenant compte de la durabilité des systèmes de production.

\section{Références}

Ahnadi C.E., Beswick N., Delbecchi L., Kennelly J.J., Lacasse P., 2002. Addition of fish oil to diets for dairy cows. II. Effects on milk fat and gene expression of mammary lipogenic enzymes. J. Dairy Res., 69, 521-531.

Angulo J., Mahecha L., Nuernberg K., Nuernberg G., Dannenberger D., Olivera M. Boutinaud M., Leroux C., Albrecht E., Bernard L., 2012. Effects of polyunsaturated fatty acids from plant oils and algae on milk fat yield and composition are associated with mammary lipogenic and SREBF1 gene expression. Animal, 6, 1961-1972.

Astrup A., Dyerberg J., Elwood P., Hermansen K., Hu F.B., Jakobsen M.U., Kok F.J., Krauss R.M., Lecerf J.M., Le Grand P., Nestel P., Risérus U., Sanders T., Sinclair A., Stender S., Tholstrup T., Willett W.C., 2011. The role of reducing intakes of saturated fat in the prevention of cardiovascular disease: where does the evidence stand in 2010? Am. J. Clin. Nutr., 93, 684-688.
Avril-Sassen S., Goldstein L.D., Stingl J., Blenkiron C., Le Quesne J., Spiteri I., Karagavriilidou K., Watson C.J., Tavare S., Miska E.A., Caldas C., 2009. Characterisation of microRNA expression in post-natal mouse mammary gland development. BMC Genomics, 10,548 .

Bao Y., Bing C., Hunter L., Jenkins J.R., Wabitsch M., Trayhurn P., 2005. Zinc-alpha2glycoprotein, a lipid mobilizing factor, is expressed and secreted by human (SGBS) adipocytes. FEBS Lett., 579, 41-47.

Baudracco J., Lopez-Villalobos N., Holmes C.W., Comeron E.A., Macdonald K.A., Barry T.N., Friggens N.C., 2012. e-Cow: an animal model that predicts herbage intake, milk yield and live weight change in dairy cows grazing temperate pastures, with and without supplementary feeding. Animal, 6, 980-993.

Bauman D.E., Griinari J.M., 2000. Regulation and nutritional manipulation of milk fat. Low-fat milk syndrome. Adv. Exp. Med. Biol., 480, 209-216.

Baumgard L.H., Corl B.A., Dwyer D.A., Saebo A., Bauman D.E, 2000. Identification of the conjugated linoleic acid isomer that inhibits milk fat synthesis. Am. J. Physiol. Regul. Integr. Comp. Physiol., 278, 179-184.

Beauvallet C., Bevilacqua C., Badaoui B., Cebo C., Makhzami S., Pollet S., Chanat E., Martin P., 2008. Accumulation of caseins in the endoplasmic reticulum of mammary epithelial cells due to $\alpha$ s1-casein deficiency, induces a chronic ER stress and a milk protein composition signing a singular secretion mode. $8^{\text {th }}$ Siena Meeting from genome to proteome: integration and proteome completion, Siena, Italy, August $31^{\text {st }}-$ September $4^{\text {th }}, 2008$.

Bernard L., Leroux C., Bonnet M., Rouel J., Martin P., Chilliard Y., 2005a. Expression and nutritional regulation of lipogenic genes in mammary gland and adipose 
tissues of lactating goats. J. Dairy Res., 72, $250-255$

Bernard L., Rouel J., Leroux C., Ferlay A., Faulconnier Y., Legrand P., Chilliard Y., 2005b. Mammary lipid metabolism and fatty acid secretion in Alpine goats fed vegetable lipids. J. Dairy Sci., 88, 1478-1489.

Bernard L., Leroux C., Chilliard Y., 2008 Expression and nutritional regulation of lipogenic genes in the ruminant lactating mammary gland. Adv. Exp. Med. Biol., 606, 67-108.

Bernard L., Bonnet M., Leroux C. Shingfield K.J., Chilliard Y., 2009a. Effect of sunflower-seed oil and linseed oil on tissue lipid metabolism, gene expression and milk fatty acid secretion in alpine goats fed maize silage based diets. J. Dairy Sci., 92, 6083-6094.

Bernard L., Leroux C., Faulconnier Y., Durand D., Shingfield K.J., Chilliard Y., 2009b. Effect of sunflower-seed oil or linseed oil on milk fatty acid secretion and lipogenic gene expression in goats fed hay-based diets. J. Dairy Res., 76, 241-248.

Bernard L., Mouriot J., Rouel J., Glasser F. Capitan P., Pujos-Guillot E., Chardigny J.M., Chilliard Y., 2010. Effects of fish oil and starch added to a diet containing sunflower-seed oil on dairy goat performance, milk fatty acid composition and in vivo delta9-desaturation of [13C]vaccenic acid. Br. J. Nutr., 104, 346-354

Bevilacqua C., Makhzami S., Helbling J.C. Defrenaix P., Martin P., 2010. Maintaining RNA integrity in a homogeneous population of mammary epithelial cells isolated by Laser Capture Microdissection. BMC Cell Biol., 11, 95.

Bionaz, M., Loor J.J., 2008. Gene networks driving bovine milk fat synthesis during the lactation cycle. BMC Genomics, 9, 366.

Boichard D., Grohs C., Bourgeois F. Cerqueira F., Faugeras R., Neau A., Rupp R., Amigues Y., Boscher M.Y., Levéziel H., 2003. Detection of genes influencing economic traits in three French dairy cattle breeds. Genet. Sel. Evol., 35, 77-101.

Brochard M., Boichard D., Ducrocq V. Fritz S., 2013. La sélection pour des vaches et une production laitière plus durables : acquis de la génétique et opportunités offertes par la sélection génomique. In : Numéro spécial, La vache et le lait. Faverdin P., Leroux C., Baumont R. (Eds). INRA Prod. Anim., 26, 145-156.

Cebo C., Lopez C., Henry C., Beauvallet C., Ménard O., Bevilacqua C., Bouvier F., Cailla H., Martin P., 2012. Goat as1-casein genotype affects milk fat globule physicochemical properties and the composition of the milk fat globule membrane. J. Dairy Sci., 95, 62156229.

Chanat E., Martin P., Ollivier-Bousquet M. 1999. Alpha(S1)-casein is required for the efficient transport of beta- and kappa-casein from the endoplasmic reticulum to the Golgi apparatus of mammary epithelial cells. J. Cell Sci., 112 3399-3412.

Chilliard Y., Bocquier F., Doreau M., 1998. Digestive and metabolic adaptations of ruminants to undernutrition, and consequences on reproduction. Reprod. Nutr. Dev., 38, 131-152.

Chilliard Y., Bonnet M., Delavaud C., Faulconnier Y., Leroux C., Djiane J., Bocquier F., 2001. Leptin in ruminants. Gene expression in adipose tissue and mammary gland, and regulation of plasma concentration. Domest. Anim. Endocrinol., 21, 271-295.
Chilliard Y., Rouel J., Leroux C., 2006. Goat's alpha-s1 casein genotype influences its milk fatty acid composition and delta-9 desaturation ratios. Anim. Feed Sci. Technol., 131, 474-487.

de Andrade P.V., Schmidely P., 2006. Effect of duodenal infusion of trans10,cis12-CLA on milk performance and milk fatty acid profile in dairy goats fed high or low concentrate diet in combination with rolled canola seed. Reprod. Nutr. Dev., 46, 31-48.

Dessauge F., Lollivier V., Ponchon B., Bruck-maier R., Finot L., Wiart S., Cutullic E., Disen-haus C., Barbey S., Boutinaud M., 2011. Effects of nutrient restriction on mammary cell turnover and mammary gland remodeling in lactating dairy cows. J. Dairy Sci., 94, 4623 4635

Devinoy E., Rijnkels M., 2010. Epigenetics in mammary gland biology and cancer. J Mammary Gland Biol. Neoplasia, 15, 1-4.

Esau C., Davis S., Murray S.F., Yu X.X., Pandey S.K., Pear M., Watts L., Booten S.L. Graham M., McKay R., Subramaniam A. Propp S., Lollo B.A., Freier S., Bennett C.F. Bhanot S., Monia B.P., 2006. miR-122 regulation of lipid metabolism revealed by in vivo antisense targeting. Cell Metab., 3, 87-98.

Faucon F., Rebours E., Bernard L., Hurtaud C., Miranda G., Menard O., Dhorne-Pollet S. Bevilacqua C., Larroque H., Gallard Y. Leroux C., Martin P., 2008. Effet du polymorphisme (AA/GC) au locus DGAT1 sur l'activité transcriptionnelle du tissu mammaire bovin, sur la composition du lait et sur les caractéristiques des globules gras et des micelles de caséines. Renc. Rech. Rum., 435-438.

Fenech M., El-Sohemy A., Cahill L. Ferguson L.R., French T.A.C., Tai E.S., Milner J., Koh W.P., Xieg L., Zucker M., Buckley M., Cosgrove L., Lockett T., Fung K.Y.C., Head R., 2011. Nutrigenetics and nutrigenomics: viewpoints on the current status and applications in nutrition research and practice. $J$ Nutrigenet. Nutrigenomics, 4, 69-89.

Ferlay A., Martin B., Pradel P., Coulon J.B., Chilliard Y., 2006. Influence of grass-based diets on milk fatty acid composition and milk lipolytic system in Tarentaise and Montbeliarde cow breeds. J. Dairy Sci. 89, 40264041

Ferlay A., Graulet B., Chilliard Y., 2013 Maîtrise par l'alimentation des teneurs en acides gras et en composés vitaminiques du lait de vache. In : Numéro spécial, La vache et le lait. Faverdin P., Leroux C., Baumont R. (Eds). INRA Prod. Anim., 26, 177-192.

Gajewska M., Gajkowska B., Motyl T. 2005. Apoptosis and autophagy induced by TGF-B1 in bovine mammary epithelial BME-UV1 cells. J. Physiol. Pharmacol., 56, 143-157.

Gervais R., McFadden J.W., Lengi A.J., Corl B.A., Chouinard P.Y., 2009. Effects of intravenous infusion of trans-10, cis-12 18:2 on mammary lipid metabolism in lactating dairy cows. J. Dairy Sci., 92, 5167-5177.

Glasser F., Ferlay A., Doreau M., Schmidely P., Sauvant D., Chilliard Y., 2008. Long-chain fatty acid metabolism in dairy cows: a metaanalysis of milk fatty acid yield in relation to duodenal flows and de novo synthesis. J. Dairy Sci., 91, 2771-2785.

Greene S.B., Gunaratne P.H., Hammond S.M., Rosen J.M., 2010. A putative role for micro RNA-205 in mammary epithelial cell progenitors. J. Cell Sci., 123, 606-618.

Grisart B., Coppieters W., Farnir F., Karim L., Ford C., Berzi P., Cambisano N., Mni M., Reid S., Simon P., Spelman R., Georges M., Snell R., 2002. Positional candidate cloning of a QTL in dairy cattle: identification of a missense mutation in the bovine DGAT1 gene with major effect on milk yield and composition. Genome Res., 12, 222-231.

Grisart B., Farnir F., Karim L., Cambisano N., Kim J.J., Kvasz A., Mni M., Simon P., Frere J.M., Coppieters W., Georges M., 2004. Genetic and functional confirmation of the causality of the DGAT1 K232A quantitative trait nucleotide in affecting milk yield and composition. Proc. Natl. Acad. Sci. USA, 101, 2398-2403

Grosclaude F., Ricordeau G., Martin P., Remeuf F., Vassal L., Bouillon J., 1994. Du gène au fromage : le polymorphisme de la caséine alpha s1 caprine, ses effets, son évolution. INRA Prod. Anim., 7, 3-19.

Gu Z., Eleswarapu S., Jiang H., 2007. Identification and characterization of micro RNAs from the bovine adipose tissue and mammary gland. FEBS Lett., 581, 981-988.

Guinard-Flament J., Marnet P.G., VerdierMetz I., Hurtaud C., Montel M.C., Stelwagen K., Pomiès D., 2013. La traite, un outil de pilotage du troupeau et de la maîtrise de la qualité du lait en élevage bovin laitier. In : Numéro spécial, La vache et le lait. Faverdin P. Leroux C., Baumont R. (Eds). INRA Prod. Anim., 26, 193-206.

Harvatine K. J., Bauman D. E., 2006. SREBP1 and thyroid hormone responsive spot 14 (S14) are involved in the regulation of bovine mammary lipid synthesis during dietinduced milk fat depression and treatment with CLA. J. Nutr., 136, 2468-2474.

Hata T., Murakami K., Nakatani H., Yamamoto Y. Matsuda T. Aoki N. 2010. Isolation of bovine milk-derived microvesicles carrying mRNAs and microRNAs. Biochem. Biophys. Res. Commun, 396, 528-533.

Horie T., Ono K., Horiguchi M., Nishi H., Nakamura T., Nagao K., Kinoshita M., Kuwabara Y., Marusawa H., Iwanaga Y., Hasegawa K., Yokode M., Kimura T., Kita T. 2010. MicroRNA-33 encoded by an intron of sterol regulatory element-binding protein 2 (Srebp2) regulates HDL in vivo. Proc. Natl. Acad. Sci. USA, 107, 17321-17326.

Ibarra I., Erlich Y., Muthuswamy S.K. Sachidanandam R., Hannon G.J., 2007. A role for microRNAs in maintenance of mouse mammary epithelial progenitor cells. Genes Dev., 21, 3238-3243.

Kadegowda A.K., Bionaz M., Piperova L.S., Erdman R.A., Loor J.J., 2009. Peroxisome proliferator-activated receptor-gamma activation and long-chain fatty acids alter lipogenic gene networks in bovine mammary epithelial cells to various extents. J. Dairy Sci., 92, 4276-4289.

Lahouassa H., Beauvallet C., Badaoui B. Martin P., Chanat E., 2009. Impact of CSN1S1 (alpha S1-casein) deficiency on the endoplasmic reticulum protein profile, in mammary epithelial cells. Congrès Exocytose-Endo- cytose, 4-6 juin 2009, Presqu’̂̂le de Giens, France.

Le Guillou S., Sdassi N., Laubier J., Passet B., Vilotte M., Castille J., Laloë D., Polyte J., Bouet S., Jaffrezic F., Cribiu E.P., Vilotte J.L., Le Provost F., 2012. Overexpression of miR$30 \mathrm{~b}$ in the developing mouse mammary gland 
causes a lactation defect and delays involution. PLoS One, 7, e45727.

Lengi A.J., Corl B.A., 2007. Identification and characterization of a novel bovine stearoylCoA desaturase isoform with homology to human SCD5. Lipids, 42, 499-508.

Leroux C., Le Provost F., Petit E., Bernard L., Chilliard Y., Martin P., 2003. Real-time RT-PCR and cDNA macroarray to study the impact of the genetic polymorphism at the alphas1-casein locus on the expression of genes in the goat mammary gland during lactation. Reprod. Nutr. Dev., 43, 459-469.

Lock A.L., Rovai M., Gipson T.A., de Veth M.J., Bauman D.E., 2008. A conjugated linoleic acid supplement containing trans-10, cis12 conjugated linoleic acid reduces milk fat synthesis in lactating goats. J. Dairy Sci., 91, 3291-3299.

Lynn F.C., 2009. Meta-regulation: microRNA regulation of glucose and lipid metabolism. Trends Endocrinol. Metab., 20, 452-459.

Mach N., Jacobs A.A., Kruijt L., van Baal J., Smits M.A., 2011. Alteration of gene expression in mammary gland tissue of dairy cows in response to dietary unsaturated fatty acids. Animal, 5, 1217-30.

Marquart T.J., Allen R.M., Ory D.S., Baldan A., 2010. miR-33 links SREBP-2 induction to repression of sterol transporters. Proc. Natl. Acad. Sci. USA, 107, 12228-12232.

Martin P., Ferranti P., Leroux C., Addeo F., 2003. Non-bovine caseins: quantitative variability and molecular diversity. In: Advanced Dairy Chemistry, Vol 1: Proteins, $3^{\text {rd }}$ Ed., Fox P.F., McSweeney P.L.H. (Eds). New York, NY: Kluwer Academic/Plenum Publishers, 277-317.

Massart-Leen A.M., Peeters G., 1985. Changes in the fatty acid composition of goat milk fat after a 48-hour fast. Reprod. Nutr. Dev., 25, 873-881.

Milenkovic D., Deval C., Gouranton E. Landrier J.F., Scalbert A., Morand C., Mazur A., 2012. Modulation of miRNA expression by dietary polyphenols in apoE deficient mice: a new mechanism of the action of polyphenols. PLoS One, 7, e29837.

Moore K.J., Rayner K.J., Suarez Y., Fernandez- Hernando C., 2010. microRNAs and cholesterol metabolism. Trends Endocrinol. Metab., 21, 699-706.

Mosley E.E., Nudda A., Corato A., Rossi E., Jenkins T., McGuire M.A., 2006. Differential biohydrogenation and isomerization of [U(13)C]oleic and [1-(13)C]oleic acids by mixed ruminal microbes. Lipids, 41, 513-517.

Mutch D.M., Wahli W., Williamson G., 2005. Nutrigenomics and nutrigenetics: the emerging faces of nutrition. FASEB J., 19 1602-1616.
Ollier S., Robert-Granié C., Bes S., Goutte M., Faulconnier Y., Chilliard Y., Leroux C. 2006. Impact of nutrition on mammary transcriptome and its interaction with the CSN1S1 genotype in lactating goats. In: Book of Abstracts, 57th Ann. Meet. Eur. Assoc. Anim. Prod., Antalya, Turkey, 17-20 September 2006, Wageningen Acad. Publ. (NL), 49p.

Ollier S., Robert-Granie C., Bernard L., Chilliard Y., Leroux C., 2007. Mammary transcriptome analysis of food-deprived lactating goats highlights genes involved in milk secretion and programmed cell death. J. Nutr., 137, 560-567.

Ollier S., Chauvet S., Martin P., Chilliard Y., Leroux C., 2008. Goat's alphaS1-casein polymorphism affects gene expression profile of lactating mammary gland. Animal, 2, 566573.

Ollier S., Leroux C., de la Foye A., Bernard L., Rouel J., Chilliard Y., 2009. Whole intact rapeseeds or sunflower oil in high-forage or high-concentrate diets affects milk yield, milk composition, and mammary gene expression profile in goats. J. Dairy Sci., 92, 5544-5560.

Pagano R.I., Pennisi P., Valenti B., Lanza M., Di Trana A., Di Gregorio P., De Angelis A., Avondo M., 2010. Effect of CSN1S1 genotype and its interaction with diet energy leve on milk production and quality in Girgentana goats fed ad libitum. J. Dairy Res., 77, 245-51.

Peterson D.G., Matitashvili E.A. Bauman D.E., 2003. Diet-induced milk fat depression in dairy cows results in increased trans-10, cis-12 CLA in milk fat and coordinate suppression of mRNA abundance for mammary enzymes involved in milk fat synthesis. J. Nutr., 133, 3098-3102.

Piperova L.S., Teter B.B., Bruckental I., Sam-pugna J., Mills S.E., Yurawecz M.P., Fritsche J., Ku K., Erdman R.A., 2000. Mammary lipogenic enzyme activity, trans fatty acids and conjugated linoleic acids are altered in lactating dairy cows fed a milk fatdepressing diet. J. Nutr., 130, 2568-2574.

Reinhardt T.A., Lippolis J.D., Nonnecke B.J., Sacco R.E., 2012. Bovine milk exosome proteome. J. Proteomics, 75, 1486-1492.

Ross S.A., Davis C.D., 2011. MicroRNA, nutrition, and cancer prevention. Adv. Nutr., 2, 472-485.

Schennink A., Stoop W.M., Visker M.H Heck J.M., Bovenhuis H., van der Poel J.J., van Valenberg H.J., van Arendonk J.A., 2007. DGAT1 underlies large genetic variation in milk-fat composition of dairy cows. Anim. Genet., 38, 467-473.

Sdassi N., Silveri L., Laubier J., Tilly G. Costa J., Layani S., Vilotte J.L., Le Provost F. 2009. Identification and characterization of new miRNAs cloned from normal mouse mammary gland. BMC Genomics, 10, 149.
Singh K., Erdman R.A., Swanson K.M., Molenaar A.J., Maqbool N.J., Wheeler T.T., Arias J.A., Quinn-Walsh E.C., Stelwagen K., 2010. Epigenetic regulation of milk production in dairy cows. J. Mammary Gland Biol. Neoplasia, 15, 101-112.

Shingfield K.J., Rouel J., Chilliard Y., 2009. Effect of calcium salts of a mixture of conjugated linoleic acids containing trans-10, cis-12 in the diet on milk fat synthesis in goats. Br. J. Nutr., 101, 1006-1019.

Steinberg S.J., Morgenthaler J., Heinzer A.K., Smith K.D., Watkins P.A., 2000. Very long-chain acyl-CoA synthetases. Human "bubble-gum" represents a new family of proteins capable of activating very long-chain fatty acids. J. Biol. Chem., 275, 35162-35169.

Tanaka T., Haneda S., Imakawa K., Sakai S., Nagaoka K., 2009. A microRNA, miR-101a, controls mammary gland development by regulating cyclooxygenase-2 expression. Differentiation, $77,181-187$

Ucar A., Vafaizadeh V., Jarry H., Fiedler J., Klemmt P.A., Thum T., Groner B., Chowdhury K., 2010. miR-212 and miR-132 are required for epithelial stromal interactions necessary for mouse mammary gland development. Nat. Genet., 42, 1101-1108.

Wang C., Li Q., 2007. Identification of differentially expressed microRNAs during the development of Chinese murine mammary gland. J. Genet. Genomics, 34, 966-973.

Winter A, Kramer W, Werner F.A, Kollers S., Kata S., Durstewitz G., Buitkamp J., Womack J.E., Thaller G., Fries R., 2002. Association of a lysine-232/alanine polymorphism in a bovine gene encoding acyl-CoA: diacylglycerol acyltransferase (DGAT1) with variation at a quantitative trait locus for milk fat content. Proc. Natl. Acad. Sci. USA, 99, 9300-9305.

Wickramasinghe S., Rincon G., Islas-Trejo A., Medrano J.F., 2012. Transcriptional profiling of bovine milk using RNA sequencing. BMC Genomics, 13, 45.

Winter A., Kramer W., Werner F.A., Kollers S., Kata S., Durstewitz G., Buitkamp J., Womack J.E., Thaller G., Fries R., 2002. Association of a lysine-232/alanine polymorphism in a bovine gene encoding acyl-CoA: diacylglycerol acyltransferase (DGAT1) with variation at a quantitative trait locus for milk fat content. Proc. Natl. Acad. Sci. USA, 99, 9300-9305.

Zidi A., Amills M., Tomas A., Vidal O., Ramirez O., Carrizosa J., Urrutia B., Serradilla J.M., Clop A., 2010. Short communication: genetic variability in the predicted microRNA target sites of caprine casein genes. J. Dairy Sci., 93, 1749-1753. 


\title{
Résumé
}

La glande mammaire est l'organe dans lequel est synthétisé et sécrété le lait. Ces processus mettent en jeu des mécanismes moléculaires dont la régulation reste incomplètement élucidée. Aussi, de nombreuses recherches ont pour objectif d'identifier les leviers permettant de moduler la composition du lait, afin de répondre à la demande de la filière et des consommateurs, et de préciser leurs mécanismes d'action pour en permettre une régulation aussi fine que possible. L'objectif de cet article est de présenter les derniers travaux relatifs à la caractérisation de facteurs génétiques et nutritionnels puis d'exposer quelques données mettant en lumière les conséquences de leurs interactions sur la lactation. Deux exemples d'études des effets de polymorphismes génétiques sur le fonctionnement mammaire chez les caprins (locus CSN1S1, spécifiant la caséine as1) et les bovins (locus DGAT1 spécifiant la diacylglycérol acyltransferase 1) mettent en exergue les différences d'expression de gènes impliqués dans le métabolisme des lipides, mais aussi identifient des gènes impliqués dans le trafic vésiculaire et la réponse «Unfolded Protein Responses » (UPR) des caprins. Des exemples de régulation nutritionnelle du métabolisme lipidique révèlent la différence de réponse à la supplémentation lipidique entre la vache et la chèvre. De plus, des approches globales ont permis la découverte de gènes du métabolisme lipidique (tels que $A C S B G 1$ et $A Z G P 1$ qui spécifient respectivement la lipidosine et la zinc- $\alpha 2$-glycoprotéine) dont l'expression mammaire était jusqu'alors inconnue, ou encore de révéler des modifications de la dynamique cellulaire mammaire. Enfin, les interactions entre les facteurs génétique et nutritionnel sont illustrées par des mécanismes de régulation fine de l'expression génique mettant en jeu de petits ARN non-codants : les microARN. L'ensemble de ces nouvelles données laissent entrevoir de nombreuses perspectives de recherche ciblant une connaissance de plus en plus exhaustive et fine du fonctionnement de la glande mammaire, mais aussi la nécessité de replacer ce fonctionnement au niveau de l'animal.

\begin{abstract}

\section{The function of lactation: regulation of biosynthesis of the milk components}

The mammary gland is the organ in which biosynthesis and secretion of milk take place. These processes involve complex molecular mechanisms for which the regulation remains largely unknown. Many studies are being conducted aiming to identify the factors that can modulate the composition of milk to meet the demand of the industry and consumers as well as to identify underlying mechanisms of action and regulation, as precisely as possible. The objective of this paper was to review our current knowledge on the characterisation of genetic and nutritional factors as well as data highlighting the consequences of their interactions on lactation. Two studies on the effects of genetic polymorphisms on the mammary functioning in goats (CSN1S1 locus specifying aS1-casein) and cattle (DGAT1 locus specifying diacylglycerol acyltransferase 1) have allowed highlighting genes involved in lipid metabolism differentially expressed, but also identifying genes involved in vesicular trafficking and "Unfolded Protein Response" in goats. Examples of nutritional regulation of lipid metabolism with inter-species specific regulation (e.g.: differences in the response to lipid supplementation between dairy cows and goats), and examples of the use of holistic approaches allowing the discovery of genes for lipid metabolism, (e.g.: ACSBG1 and $A Z G P 1$, specifying respectively lipidosin and zinc-a2-glycoprotein, for which expression in mammary gland has until now remained unknown) or revealing changes in mammary cell dynamics. Finally, interactions between genetic and nutritional factors are presented through a description of regulatory molecular mechanisms of gene expression involving small non coding RNA: microRNA. Taken together, these new data suggest many potentials of research towards more comprehensive and precise understanding of the lactating mammary gland functioning.
\end{abstract}

LEROUX C., BERNARD L., DESSAUGE F., LE PROVOST F., MARTIN P., 2013. La fonction de lactation : régulation de la biosynthèse des constituants du lait. In : Numéro spécial, La vache et le lait. Faverdin P., Leroux C., Baumont R. (Eds). INRA Prod. Anim., 26, 2, 117-128. 